\title{
Effects of Acidic Amino Acid Antagonists Upon the Spectral Properties of Carp Horizontal Cells: Circuitry of the Outer Retina ${ }^{1}$
}

\author{
STUART C. MANGEL, ${ }^{2}$ MICHAEL ARIEL, ${ }^{3}$ AND JOHN E. DOWLING \\ The Biological Laboratories, Harvard University, Cambridge, Massachusetts 02138
}

\begin{abstract}
The acidic amino acid receptor antagonists, $\alpha$-methylglutamate and $\alpha$-aminoadipate, were applied to the carp retina to study their effects upon the spectral properties of horizontal cells and to elucidate the synaptic connections between horizontal cells and cones. Application of these antagonists strongly hyperpolarized the L-type cone horizontal cells and reduced the responses of these horizontal cells to red light more than to blue light. Application of $\mathrm{Co}^{2+}$ ions to the retina, a procedure which decreases transmitter release, also hyperpolarized the L-type cone horizontal cells but reduced the response of these horizontal cells to red and blue lights equally. These results suggest that red- or long wavelengthsensitive cones release a different transmitter onto L-type cone horizontal cells than do short wavelength-sensitive cones.

Application of the acidic amino acid antagonists also revealed details of the feedback pathway from L-type cone horizontal cells to cones. Previous studies have shown that feedback varies directly with stimulus size and that the effects of feedback on the responses of cones are observed as a transient waveform at response onset (a large, hyperpolarizing potential that is quickly followed by a smaller plateau potential). Application of the acidic amino acid antagonists at a dose which partially hyperpolarized the horizontal cells selectively enhanced the response of the cells to blue lights, when full field, and not spot, stimuli were used. The antagonists also eliminated the transient at response onset. These findings are consistent with the presence of a feedback pathway from L-type cone horizontal cells to short wavelength cones but not to long (red-sensitive) cones.
\end{abstract}

Retinal horizontal cells make synaptic contacts in the outer plexiform laycr and transmit information from photorcceptor colls to other photoreceptors and to bipolar cells. In the fish retina, horizontal cells

Received March 14, 1984; Revised May 13, 1985;

Accepted May 13, 1985

\footnotetext{
${ }^{1}$ We wish to thank Dr. D. Marshak for his critical reading of this manuscript. We are also extremely grateful to MS. S. Levinson for the typing of this manuscript and to Ms. P. Sheppard for the preparation of the figures. This research was supported in part by National Institutes of Health Grant EY00824 (J. C. D.) and by National Institutes of Health Postdoctoral Fellowships EY 05458 (S. C. M.) and EY-05500 (M. A.).

${ }^{2}$ To whom correspondence should be sent, at his present address: Department of Ophthalmology, Washington University School of Medicine, 660 South Euclid Avenue, St. Louis, MO 63110.

${ }^{3}$ Prosent addross: University of Pittsburgh, Psychobiology Program, 458 Crawford Hall, Pittsburgh, PA 15260
}

respond to light flashes with sustained graded potentials (S-potentials) that code spectral information in several ways (MacNichol and Svaetichin, 1958; Tomita, 1965). Luminosity horizontal cells (L-type) respond with hyperpolarizations to all wavelengths of visible light and are activated either by cones or by rods. Chromaticity horizontal cells (C-type) receive cone input and are of two types: a biphasic cell, so called because it depolarizes to long wavelengths of light and hyperpolarizes to shorter wavelengths of light, and a triphasic cell, so called because it hyperpolarizes to long and short wavelengths of light but depolarizes to intermediate wavelengths (Kaneko and Yamada, 1972; Mitari et al., 1974). Stell and Lightfoot (1975) have postulated a system of feedforward and feedback synaptic connections between horizontal cells and cones that may account for the various spectral responses of these different cone horizontal cells, and in the fish and turtle, physiological evidence has likewise suggested that feedback connections from horizontal cells to cones relay information about the receptive field periphery (Baylor et al., 1971; Fuortes et al., 1973; Burkhardt, 1977; Piccolino and Gerschenfeld, 1980; Toyoda and Kujiraoka, 1982).

Amino acids may serve as neurotransmitters in these synaptic connections. It has been proposed that an acidic amino acid, such as L-glutamate or L-aspartate, is released by photoreceptors in the dark so that a depolarization of the horizontal cell membrane is produced (Cervetto and MacNichol, 1972; Dowling and Ripps, 1972; Murakami et al., 1972; Wu and Dowling, 1978; Ishida and Fain, 1981; Lasater and Dowling, 1982). In turn, some horizontal cells may release $\gamma$-aminobutyric acid (GABA) back onto cones (Lam et al., 1979; Wu and Dowling, 1980).

Although an acidic amino acid may be released by red- and greensensitive cones, recent evidence suggests that blue cones may not use these substances as a neurotransmitter. Marc and Lam (1981a) and Kleinschmidt (1982) have reported that red- and green-sensitive cones accumulate labeled glutamate and aspartate but that blue cones do not. Moreover, the resporises of cone horizontal cells to red stimuli may be more affected by the application of aspartate than the responses to blue lights (Murakami et al., 1972). Accordingly, to test whether blue cones use a different transmitter than red and green cones, we examined the responses of cone horizontal cells to spectral stimuli during the application of acidic amino acid receptor antagonists. That is, the selective blocking agents, DL- $\alpha-$ aminoadipic acid and $\alpha$-methylglutamic acid were applied to the retina to determine whether the responses of cone horizontal cells to long wavelength (red) stimuli were selectively reduced. In this paper, we describe the differential effects which each of these drugs evokes on the responses of cone horizontal cells to blue and red lights.

\section{Materials and Methods \\ Preparation. Carp (Cyprinus carpio) were maintained in aerated aquaria at approximately $20^{\circ} \mathrm{C}$ and were dark-adapted for at least 20 min before an}


experiment. Their eyes were enucleated and hemisected, and the eyecups were inverted onto dry filter paper. The pigment epithelium was peeled from the retina and the optic nerve was cut. Finally, the isolated retina with receptor side up was soaked with Ringer's solution and placed in a chamber that was aerated with moist oxygen. All procedures were performed under conditions of dim red illumination and at a room temperature of about $20^{\circ} \mathrm{C}$.

A few carp received an intraocular injection of 6-hydroxydopamine $(20$ $\mu \mathrm{g} / 10 \mu \mathrm{l}$ of $0.9 \%$ saline) into one eye 6 and 7 days before the recording experiments. This procedure depletes dopamine, the interplexiform cell's transmitter, from that cell's presynaptic terminals and, thus, eliminates the influence of this synaptic input onto horizontal cells. The other eye served as a control and received similar injections of $10 \mu \mathrm{l}$ of $0.9 \%$ saline only on the same days (Negishi et al., 1981; Watling et al., 1982).

Stimulating and recording procedures. The stimulating and recording procedures have been described in detail previously (Dowling and Ripps, 1971; Hedden and Dowling, 1978; Wu and Dowling, 1978, 1980). Light stimuli were presented to the retina with a dual beam photostimulator. This apparatus provided two independent light channels such that stimulus intensity, wavelength, and size could be varied to characterize impaled cells. The duration of the light stimuli was always $500 \mathrm{msec}$. Spectral curves were obtained for each cell by the use of narrow band interference filters. These filters were adjusted to equal quantal flux with neutral density filters. Peak light intensity of the channels at $500 \mathrm{~nm}$ was $4 \times 10^{11}$ photon $/ \mathrm{cm}^{2} \mathrm{sec}$ as measured with a calibrated photodiode (PIN-5D, United Detector Technology, Santa Monica, CA).

Standard intracellular recording procedures were followed during these experiments. Micropipettes were pulled on a modified Livingston puller and filled with $4 \mathrm{M}$ potassium acetate. These pipettes typically had resistances of 150 to 600 megohms as measured at the retinal surface.

Solutions and atomizing system. The Ringer's solution of $80 \mathrm{mM} \mathrm{NaCl}$, $22.7 \mathrm{mM} \mathrm{NaHCO}_{3}, 3.5 \mathrm{mM} \mathrm{KCl}, 2.4 \mathrm{~mm} \mathrm{MgSO}_{4}, 2.3 \mathrm{~mm} \mathrm{CaCl}_{2}, 10 \mathrm{~mm}$ dextrose, and $10 \mathrm{~mm}$ HEPES was bubbled with oxygen and adjusted to $\mathrm{pH}$ 7.35 with $1 \mathrm{~N} \mathrm{HCl}$ before the start of each experiment. The amino acid receptor antagonists, $\mathrm{DL}-\alpha$-aminoadipate $(\alpha-\mathrm{AA})$ and $\alpha$-methylglutamate $(\alpha$ MG) (Sigma Chemical Co., St. Louis, MO) were dissolved in oxygenated Ringer's solution, and the $\mathrm{pH}$ was readjusted to 7.35. Cobalt chloride was added to double distilled water. All solutions were prepared on the day of the experiment.

The Ringer's and test solutions were applied to the isolated retina with fine spray nebulizers. Because the aim of the present study was to examine receptive field properties of horizontal cells during various drug applications, it was not necessary to use drug doses which generated threshold effects. Rather, we employed drug concentrations in the nebulizers sufficient to produce suprathreshold but nonsaturating effects. Slightly lower concentrations or fewer sprays produced threshold responses. Wu and Dowling (1978, 1980) have discussed the factors that determine the extent of dilution that test solutions undergo when sprayed onto the retina and have made rough estimates of drug concentrations at the horizontal cell surface. Although the drug concentrations in the nebulizers ranged between 25 and $200 \mathrm{~mm}$ in the present study, their exact concentration at the horizontal cell surface must be many times reduced. Based on a recent study (Ariel et al., 1984) that compared the efficacy of drug application onto horizontal cells by nebulizer and by superfusion, a drug concentration in the nebulizers of $100 \mathrm{~mm}$, for example, appears diluted by 20 -fold, so that its effective concentration at the retinal surface mldy be closer to $5 \mathrm{~mm}$. Moreover, mechanisms such as uptake may further distort this dilution factor.

identification of cell types. Cells were identified with appropriate patterns of Illumination (Werblin and Dowling, 1969; Kaneko, 1970). Horizontal cells were impaled between 75 and $125 \mu \mathrm{m}$ below the retinal surface and were characterized by resting membrane potentials between -20 and $-35 \mathrm{mV}$. In addition, these cells responded with graded hyperpolarizations to light, and their responses increased in size with increasingly larger spot stimuli (Naka and Rushton, 1967). Although this study deals primarily with cone horizontal cells and the effects of acidic amino acid antagonists upon them, rod horizontal cells were occasionally encountered and studied. L-type and C-type cone horizontal cells and rod horizontal cclls wcre easily distinguished by the use of spectral and intensity curves and by response waveform (Mitari et al., 1974; Hedden and Dowling, 1978).

\section{Results}

The effect of $\alpha$-MG was tested on 412 cone horizontal cells, and the effect of $\alpha$-AA was tested on 33 cone horizontal cells. Under all conditions, the effects of these two acidic amino acid receptor antagonists were similar at equivalent doses.

\section{L-type cone horizontal cells}

Spectral effects of acidic amino acid antagonists. Figures 1 and 2 illustrate the effects of these acidic amino acid antagonists upon the membrane potential and response amplitude of dark-adapted Ltype cone horizontal cells. Before drug application in each case, a rcd $(620 \mathrm{~nm})$ and a blue $(480 \mathrm{~nm})$ light were adjusted in intensity so as to generate hyperpolarizing responses of similar amplitude. As can be seen in Figure 1, application of $\alpha$-AA produced a large hyperpolarization of the membrane potential (see also $\mathrm{Wu}$ and Dowling, 1978) and a difference in the response amplitude to the red and blue lights. In particular, in Figure $1 A$ during the membrane hyperpolarization, the response to the red light virtually vanished, whereas the response to the blue light was enhanced at an intermediate level of membrane potential hyperpolarization and was then decreased slightly at full membrane potential hyperpolarization. Thus, following antagonist application, the response to blue light was always larger than the response to red light at all hyperpolarized potential levels. These phenomena are illustrated again for this cell in Figure $1 B$, which depicts the effects of a second, smaller drug application, given after complete recovery from the first application. In this case, a smaller hyperpolarization of the membrane potential was observed. Moreover, the response to the red light remained unaltered, whereas the response to the blue light was only enhanced.

The vast majority of cells tested with amino acid antagonists yielded spectral differences similar to those illustrated in Figure 1. That is, the response amplitude of the cells to blue light was greater than that to red light at all hyperpolarized potential levels following amino acid antagonist application. This is depicted again in Figure

\section{L-type Cone Horizontal Cell}
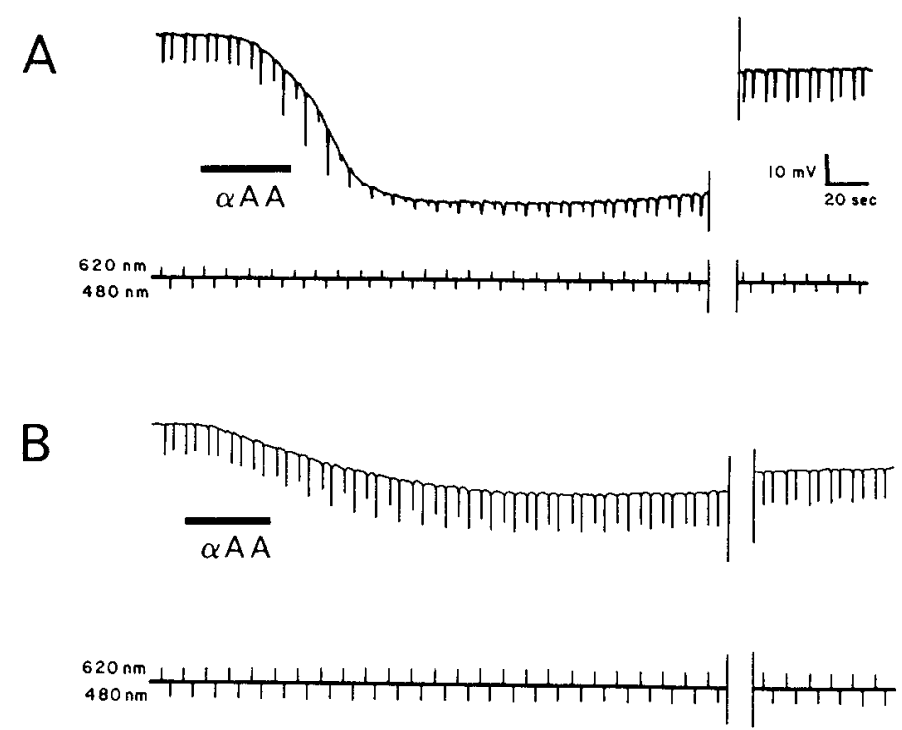

Figure 1. Effects of the acidic amino acid antagonist, $\alpha$-AA, upon the membrane potential and spectral responses of a dark-adapted L-type cone horizontal cell. Urug was applied to the retina by a fine spray nebulizer during the period indicated by the bars directly below the voltage trace. Full field, diffuse, spectral stimuli (620- and 480-nm lights) were alternately presented to the retina, as indicated by the bottom trace, and were adjusted in intensity before drug application so that the responses they generated were approximately equal. $A$, Effect of a large dose of $\alpha$-AA followed by recovery. The drug produced a large, nearly saturating hyperpolarization of the cell's membrane potential, an enhancement of the response to the $480-\mathrm{nm}$ (blue) light, and a reduction of the response to the $620 \mathrm{~nm}$ (rcd) light. $B$, Effect of a smaller dose of $\alpha$-AA upon the same cell $1 \mathrm{~min}$ later followed by recovery. This drug application produced a smaller hyperpolarization, an enhancement of the response to $480-\mathrm{nm}$ light and no reduction of the response to $620-\mathrm{nm}$ light. 


\section{L-type Cone Horizontal Cells}

A
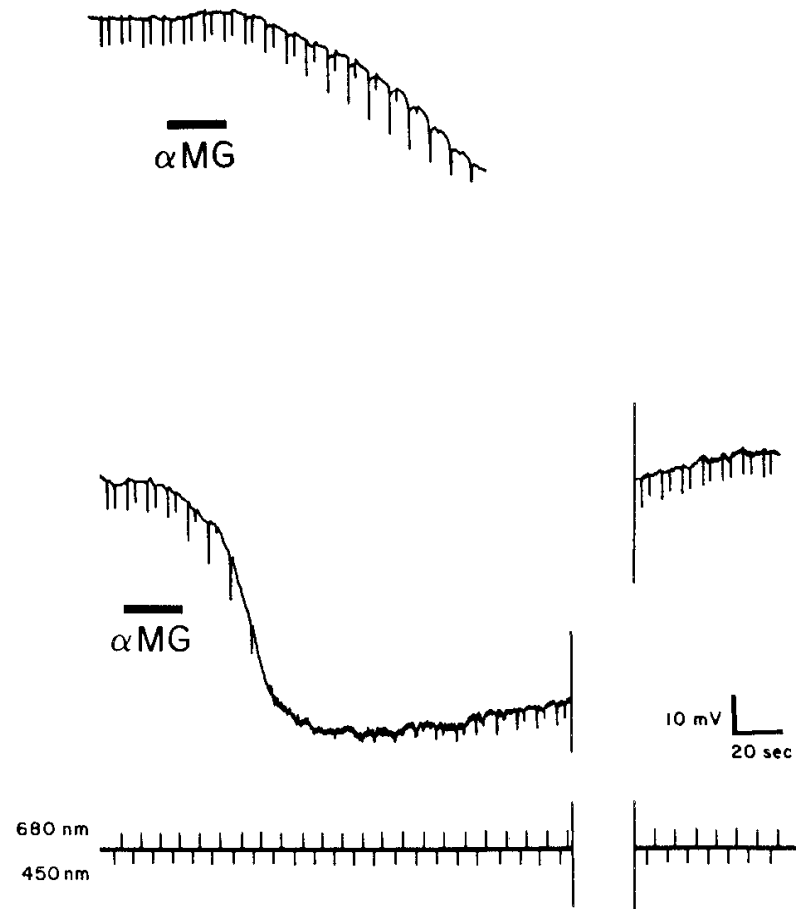

Figure 2. Effects of the acidic amino acid antagonist, $\alpha$-MG, upon the membrane potential and spcctral responses of dark adapted $L$ type cone horizontal cells. Conventions are as in Figure 1. A, Effect of a large, nearly saturating dose of $\alpha$-MG. During the membrane potential hyperpolarization, the drug enhanced the resporse of the cell to 450-rin light and eliminated the response to $680-\mathrm{nm}$ light. $B$, Effect of a large, saturating dose of $\alpha-\mathrm{MG}$ with recovery. At the peak of the hyperpolarization, the drug eliminated the responses to both 450 and $680 \mathrm{~nm}$ of light.

$2 A$, in which the response to red light was eliminated after an application of $\alpha$-MG. However, occasionally with large saturating doses of these drugs, the responses to both red and blue lights could be eliminated entirely (see Fig. $2 B$ ). Although there is a bluered response difference during tho dovolopment of the membrane potential hyperpolarization, this spectral difference disappeared at full hyperpolarization.

Although the degree of response enhancement to the blue light stimulus was typically large, spectral response curves that were obtained after antagonist application revealed that the cells remained clearly dominated by a long wavelength-sensitive input and therefore were still identifiable as L-type cone horizontal cells. However, as shown in Figure $3 A$, distinct differences did occur in the spectral response curves of L-type cone horizontal cells before and after $\alpha$ MG application. Not only were the responses in the blue region of the spectrum relatively much larger after drug application, but the responses to red lights were decreased in size and the peak response occurred at a shorter wavelength.

Synaptically blocked retinas. The spectral effects of the amino acid antagonists, $\alpha$-MG and $\alpha$-AA, upon L-type cone horizontal cells are not simply due to hyperpolarization of the cell's membrane potential but rather to a selective action of the drugs themselves. ihis conclusion was reached by the experiment illustrated in Figure $3 B$, which depicts an experiment identical to those shown in Figures 1 and 2 except that $\mathrm{Co}^{2+}$ was applied to the retina. Application of $\mathrm{Co}^{2+}$ to the dark-adapted retina decreases all transmitter release
(Cervetto and Piccolino, 1974). Therefore, $\mathrm{Co}^{2+}$ treatment produced a hyperpolarization of the membrane potential of horizontal cells as did $\alpha-\mathrm{MG}$ and $\alpha$-AA. In most cases, no concomitant difference in the rosponses to blue and red lights occurred with $\mathrm{Co}^{2+}$ treatment. In about $15 \%$ of the cases, however, the response to the blue light stimulus, compared to the red light stimulus, was slightly larger after $\mathrm{Co}^{2+}$ treatment but the differential spectral effect with $\mathrm{Co}^{2+}$ treatment was never as large as the typical spectral effect with antagonist treatment.

Involvement of the feedback pathway from horizontal cells to cones. To test the possibility that the spectral effects of acidic amino acid antagonists are mediated through the feedback connections of horizontal cells onto cones, we next applied these drugs while light stimuli of different sizes were alternatively flashed. Studies on the turtle and fish retina have shown that feedback effects upon cones increase in magnitude with stimuli that cover large areas of the receptive field periphery (Baylor et al., 1971; Fuortes et al., 1973; O'Bryan, 1973; Burkhardt, 1977; Piccolino and Gerschenfeld, 1980). One of these experiments upon a dark-adapted L-type cone horizontal cell is shown in Figure $4 A$. The intensity of a diffuse $450-\mathrm{nm}$ stimulus was initially adjusted so that it generated a response approximately equal in magnitude to that of a spot stimulus of equivalent wavelength. As can be seen, application of $\alpha$-MG enhanced the response to the diffuse stimulus relatively more than to the spot stimulus. Indeed, we found that the degree of enhancement, in general, is directly related to spot size. That is, following antagonist application, the responses of L-type cone horizontal cells to diffuse blue stimuli were markedly increased in size, whereas the responses to small blue spots were only slightly increased. Because the effect of the amino acid antagonists increases in magnitude with stimuli that cover large areas of the receptive field periphery, these results suggest that the response enhancement to blue lights is mediated through the feedback connections of horizontal cells onto cones.

Amino acid antagonist application did not increase response size to red stimuli. As illustrated in Figure $4 B$, application of $\alpha-\mathrm{MG}$ produced a hyperpolarization of the membrane potential with no concomitant effect upon the size of the cell's responses to light of $620 \mathrm{~nm}$.

As expected, response enhancement usually did not occur when $\mathrm{Co}^{2+}$ was applied to the retina. This result is shown in Figure $4 \mathrm{C}$ for a dark-adapted L-type cone horizontal cell. $\mathrm{Co}^{2+}$ treatment did not induce an enhancement of the response to either the bluc diffuse or spot stimuli. These results thus suggest that the effects of the acidic amino acid antagonists are dependent on stimulus size and wavelength and are due to a selective action of the antagonists themselves.

Effects of acidic amino acid antagonists upon response waveform. The response waveform of L-type cone horizontal cells possesses a prominent transient at response onset (a large, hyperpolarizing potential that is quickly followed by a smaller plateau potential). This phenomenon is believed to indicate the presence of tonic feedback inhibition from these horizontal cells onto cones (Baylor et al., 1971). That is, a tonic inhibitory effect of horizontal cells onto cones in the dark is reduced by light stimulation, so that the magnitude of a light-induced hyperpolarization is reduced. During a light stimulus there is an initial hyperpolarization followed, after a short latency, by a repolarization to a more depolarized level. This latter plateau potential is due to a reduction in the tonic inhibitory feedback effect of horizontal cells onto cones. This sequence of events is produced in cones and therefore is also evident in the response waveform of L-type cone horizontal cells as a prominent transient

Examples of the prominent transient in the response waveform of L-type cone horizontal cells are illustrated in Figure 5, which also shows that responses to shorter wavelength stimuli exhibit larger transients than the responses to longer wavelength stimuli. As stimulus intensity was increased, the responses to $540-\mathrm{nm}$ light developed prominent transients, whereas the responses to $650-\mathrm{nm}$ 


\section{L-type Cone Horizontal Cells}
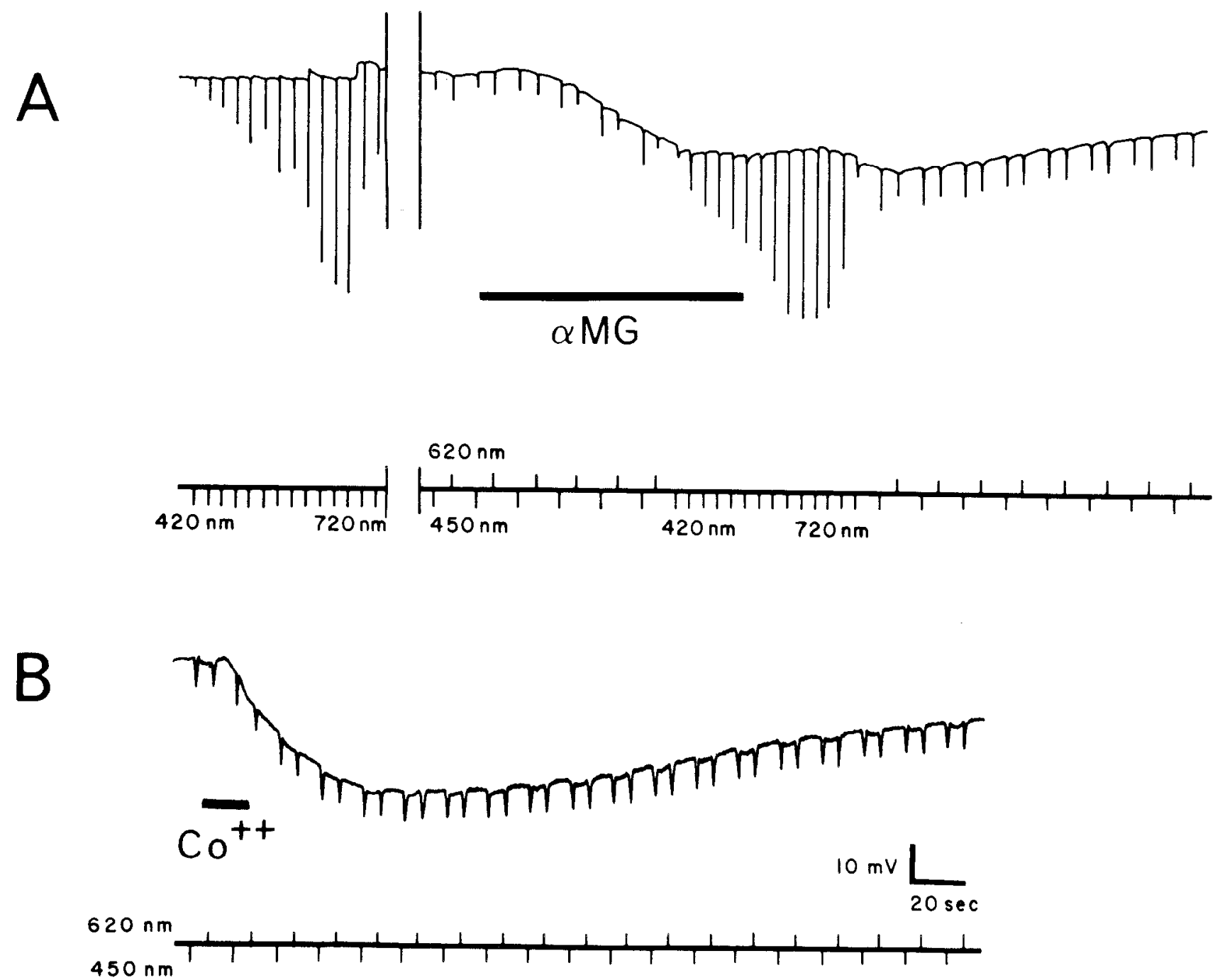

Figure 3. Comparison of the effects of an acidic amino acid antagonist, $\alpha-M G$, and of $\mathrm{Co}^{2+}$ ions upon the spectral responses of dark-adapted $\mathrm{L}$-type cone horizontal cells. Conventions are as in Figure 1. In addition, a spectral response series $(A)$ is indicated by the sequence of light pulses between 420 and $720 \mathrm{~nm}$. A, Effcct of $\alpha$-MG application upon spectral responses with recovery. Following drug application, the responses to long wavelength stimuli still predominated, although responses to shorter wavelength stimuli were enhanced. $B$, Lack of a differential spectral response effect following application of $\mathrm{Co}^{2+}$ ions. However, $\mathrm{Co}^{2+}$ treatment did produce a hyperpolarization of the membrane potential.

light did not. Moreover, this difference in response waveform was most noticeable at relatively interise but nonsaturating light intensities. Because L-type cone horizontal cells exhibit transient waveforms most clearly to short wavelength stimuli, the feedback pathway from these horizontal cells probably terminates on short wavelengthsensitive cones rather than on long wavelength-sensitive cones (Yang et al., 1982).

In addition to the effects of acidic amino acid antagonists upon response amplitude, application of these substances altered the response waveform of L-type cone horizontal cells so that the transient character of their responses was reduced or eliminated (see Fig. 6). The use of a faster sweep speed revealed that $\alpha$-MG eliminated the prominent transient that was normally observed at stimulus onset, so that the response shape became considerably rounded. This effect was apparent for the responses to both long and short wavelength stimuli but was more pronounced in the case of the responsc to short wavelength stimuli, simply because these latter responses normally exhibited larger transients. In fact, amino acid antagonist application reduced or eliminated the transient in the response of these cells to stimuli of relatively high intensity but enhanced the responses to short wavelength stimuli of relatively low intensity. Both of these effects can be attributed to a reduction in the extent of tonic inhibitory feedback from L-type cone horizontal cells to cones.

Interestingly, transients in the response waveform can be eliminated by application of a dim 480-nm background light, as shown in Figure 7. In contrast, application of a $650-\mathrm{nm}$ background light that hyperpolarized the cell's membrane potential to the same degree had no effect on the response waveform to any spectral stimulus. Thus, adaptation of the short wavelength cone with a dim 480-nm background light can eliminate transients at response onset or, in other words, can eliminate the effects of release from feedback inhibition.

Conversely, addition of a dim 500-nm light to a 650 -nm stimulus caused the response of an L-type cone horizontal cell to develop a prominent transient, as shown in Figure 8 . However, because the 


\section{L-type Cone Horizontal Cells}

A

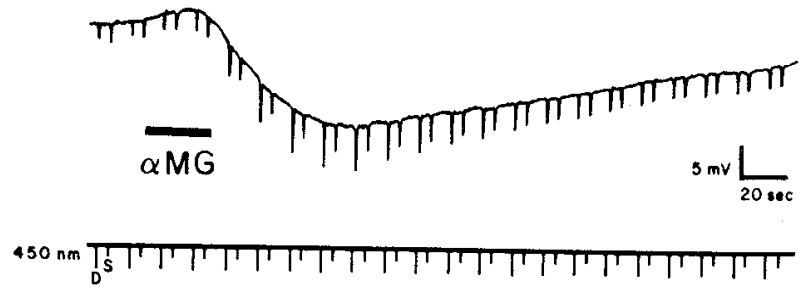

B

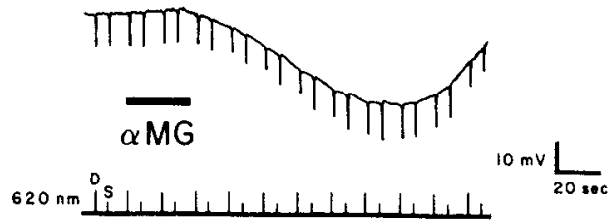

C

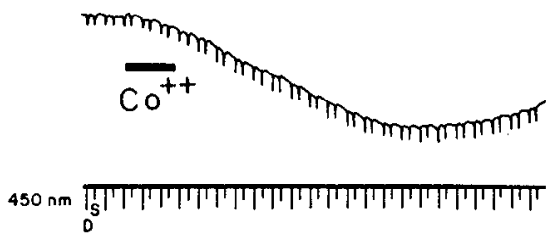

500-nm was relatively dim and ineffective on the response of horizontal cells, its addition to the 650-nm test flash did not appreciably increase the size of the cell's hyperpolarization. In contrast, simultaneous stimulation with a 410-nm test flash and a dim 500-nm light did not lead to an equivalent interaction, in which the size of the transient was increased (Fig. 8). That is, the response of the Ltype cone horizontal cell was virtually unaltered by the addition of a $\operatorname{dim} 500-\mathrm{nm}$ light to a blue, $410-\mathrm{nm}$ test flash. The presence of this interaction between the responses to 500- and 650-nm lights indicates that there are at least two cone inputs to L-type cone horizontal cells. Moreover, because this interaction occurs between intermediate $(500 \mathrm{~nm})$ and long $(650 \mathrm{~nm})$ wavelength cone pathways but not between short $(410 \mathrm{~nm})$ and intermediate $(500 \mathrm{~nm})$ wavelength pathways, photoreceptor input to L-type cone horizontal cells of the carp may be provided by long (red) wavelength-sensitive cones and only one shorter (blue or green) wavelength-sensitive cone.

Rod horizontal cells. Because rods in the fish retina may also utilize an acidic amino acid as a neurotransmitter (Marc and Lam, 1981a), application of acidic amino acid antagonists should hyperpolarize rod horizontal cells. This is the case, as depicted in Figure 9. As can be seen, application of $\alpha$-MG hyperpolarized the cell. A hyperpolarizing effect was observed in all of the cells studied $(n=5)$.

However, because rod horizontal cells receive input only from rods in the carp retina (Kaneko and Yamada, 1972) and because they do not participate in feedback pathways with rods or cones, application of acidic amino acid antagonists should not produce differential spectral response effects. This is the case. As illustrated in Figure 9, application of $\alpha$-MG did not produce a differential rod horizontal cell response to $500-$ and $680-\mathrm{nm}$ stimuli with respect to response size or waveform. Similarly, addition of a dim $500-\mathrm{nm}$ light to a $650-\mathrm{nm}$ test flash did not alter the response waveform of rod horizontal cells, as it did that of L-type cone horizontal cells.

Lack of inner retinal pathway influence. The effects of acidic amino acid antagonists upon the spectral responses of L-type cone horizontal cells are probably not mediated by inner retinal pathways. Such influence is possible via interplexiform cells, a cell type which, in the teleost, receives input from amacrine and bipolar cells and synapses onto horizontal cells (Dowling and Ehinger, 1978). Because interplexiform cells appear to release dopamine onto horizontal cells (Ehinger et al., 1969; Dowling and Ehinger, 1978), we were able to examine the influence of this synaptic input on the phenom-

Figure 5. Effects of stimulus wavelength and intensity upon the response waveform of L-type cone horizontal cells. Intensityresponse series at $540 \mathrm{~nm}$ and at $650 \mathrm{~nm}$ are depicted. The light flash denoted as -0.0 was unattenuated; other light flashes were attenuated by logarithmic noutral density filters. At relatively high intensities, responses to $540-\mathrm{nm}$ light but not to $650-\mathrm{nm}$ light exhibited prominent transients al stimulus onset. See the text for details. 


\section{L-type Cone Horizontal Cell}

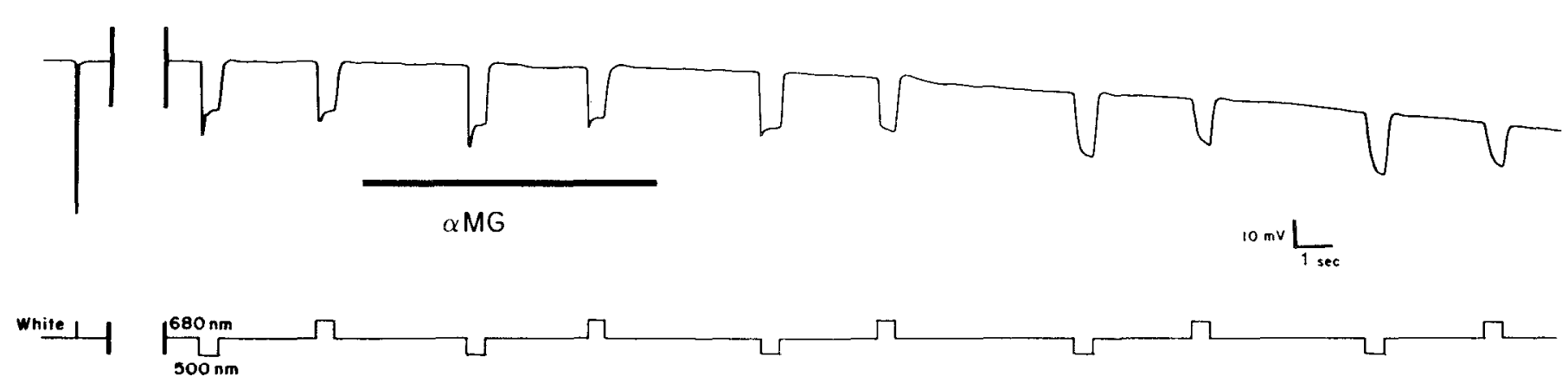

Figure 6. Effect of $\alpha$-MG upon the response waveform of an L-type cone horizontal cell. Conventions are as in Figure 1. Application of $\alpha$-MG eliminated the prominent transient normally observed at stimulus onset. See the text for details.

\section{L-type Cone Horizontal Cell}

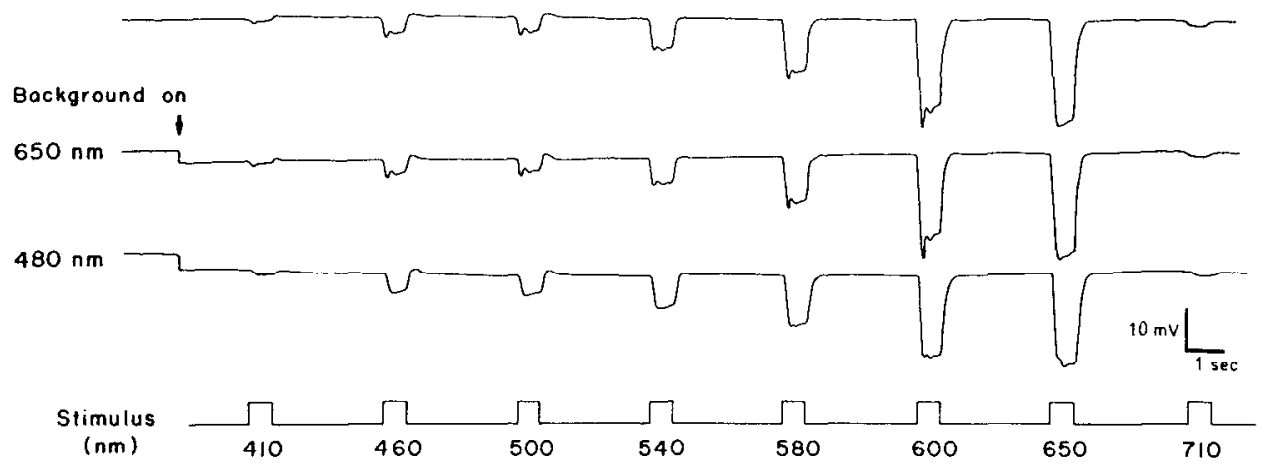

Figure 7. Effects of different spectral backgrounds upon the response waveform of $\mathrm{L}$ type cone horizontal cells. Spectral response series with no background light and with 480 $\mathrm{nm}$ or $650-\mathrm{nm}$ backgrounds are shown. Addition of a $480-\mathrm{nm}$ background light, but not a $650-\mathrm{nm}$ background, eliminated the transients at stimulus onset. ena reported here by the intravitreal injection of 6-hydroxydopamine, 1 week before the recording experiments. This procedure depletes dopamine from interplexiform cell terminals (Dowling and Ehinger, 1978; Negishi et al., 1981; Watling et al., 1982). We have found that horizontal cell responses in these treated retinas were similar to those in untreated, control retinas in terms of the effects of the amino acid antagonists (cf. Cohen and Dowling, 1983). Figure 10 depicts a typical spectral response curve from an L-type cone horizontal cell in a treated retina, as well as the effect of $\alpha$-MG upon the responses of a treated L-type cone horizontal cell to spectral stimuli. As can be seen, $\alpha-M G$ application increased the response to a $450-\mathrm{nm}$ stimulus and decreased the response to a $650-\mathrm{nm}$ stimulus. Thus, the spectral response phenomena that occur during amino acid antagonist application appear to be mediated by outer retinal pathways.

\section{C-type cone horizontal cells}

Spectral effects. Unlike L-type cone horizontal cells, application of amino acid antagonists did not enhance the response of C-type cone horizontal cells to diffuse short wavelength (blue) stimuli. Rather, responses to stimuli of intermediate wavelengths increased in size (Fig. 11A).

Application of acidic amino acid antagonists altered the spectral responses of biphasic $C$-lype horizonlal cells in yet another way. Following application of either $\alpha-\mathrm{AA}$ or $\alpha-\mathrm{MG}$, the depolarizing responses of these cells, which are normally generated with stimuli of long wavelengths, became decreased in size and often inverted to hyperpolarizations. An example of this finding is depicted in Figure $11 B$. It can be seen by a comparison of spectral response curves before and during $\alpha-\mathrm{MG}$ application that the antagonist produced a hyperpolarization of the membrane and an inversion of the cell's depolarizing response to $650-\mathrm{nm}$ light into a hyperpolarization. In addition, the depolarizing responses to longer wavelength (680 and $720 \mathrm{~nm}$ ) stimuli were abolished so that no response was present. Moreover, no evidence of a response enhancement to $450-\mathrm{nm}$ light was observed, as was also noted for the cell in Figure 11A. Thus, amino acid antagonist application eliminated the depolarizing responses of this cell and, by so doing, exposed the superimposed, hyperpolarizing responses.

$\mathrm{Co}^{2+}$ treatment, however, produced similar effects upon the spectral responses of C-type horizontal cells. That is, following application of $\mathrm{Co}^{2+}$ to the retina, the membrane of C-type cells hyperpolarized, and their depolarizing responses usually changed into hyperpolarizing responses. These phenomena are illustrated in Figure $11 \mathrm{C}$ for a biphasic C-type horizontal cell. The inversion of the depolarizing response into a hyperpolarizing response is evident from a comparison of this cell's spectral curves before and after $\mathrm{Co}^{2+}$ treatment. Interestingly, hyperpolarization of a C-type horizontal cell with a blue background light did nol elirnirate its depolarizing responses. Rather, depolarizing responses increased in magnitude with blue background lights of low and moderate intensity (Naka and Rushton, 1966a).

Amino acid antagonists and $\mathrm{Co}^{2+}$ ions also affect the spectral properties of triphasic C-type horizontal cells. That is, application of these drugs upon dark-adapted retinas produced a hyperpolarization of the cell and eliminated the cell's depolarizing responses so that the superimposed hyperpolarizing responses were exposed. Interestingly, $\alpha$-MG and $\alpha$-AA application did not enhance the hyperpolarizing responses of these $\mathrm{C}$-type cells to any spectral stimuli. These phenomena are shown in Figure 12, $A$ and $B$, for one triphasic cell 
and in Figure $12 \mathrm{C}$ for a second triphasic cell. The effects of $\alpha-\mathrm{MG}$ are depicted in Figure $12 \mathrm{~A}$ and the similar effects of $\mathrm{Co}^{2+}$ are depicted in Figure 12B. Figure 12C illustrates particularly clearly, at a laster sweep speed, that antagonist application eliminates the depolarizing responses of this C-type cell so that the same spectral stimuli now evoke the superimposed, hyperpolarizing responses. Thus, whether the depolarizing responses of C-type horizontal cells occur to stimuli of intermediate (triphasic cells) or long (biphasic cells) wavelengths, application of either the acidic amino acid antagonists or the $\mathrm{Co}^{2+}$ ions reduces or eliminates them.

\section{Discussion}

Effects of amino acid antagonists upon the spectral response properties of L-type cone horizontal cells. The finding that acidic amino antagonists, such as $\alpha-\mathrm{MG}$ and $\alpha$-AA, decrease the response of L-type cone horizontal cells to red lights but not to blue lights,

\section{L-type Cone Horizontal Cell}

Test colors

Figure 8. Influence of a dim 500-nm light stimulus upon the response waveform of $L$ type cone horizontal cells. Responses to test lights of $410 \mathrm{~nm}$ (top trace), $500 \mathrm{~nm}$ (middle trace), and $650 \mathrm{~nm}$ (bottom trace) at low and at high intensities are shown, by themselves, and in conjunction with a dim 500 -nm light stimulus. Addition of the dim $500-\mathrm{nm}$ stimulus to the bright $650 \mathrm{~nm}$ stimulus produced a prominent transient in the response of the cell, but addition of the dim $500-\mathrm{nm}$ light to either the $410-\mathrm{nm}$ or the 500 $\mathrm{nm}$ lights did not alter the response waveform. Response size to the spectral test lights was not appreciably increased in any of the cases by addition of the dim 500-nm light.

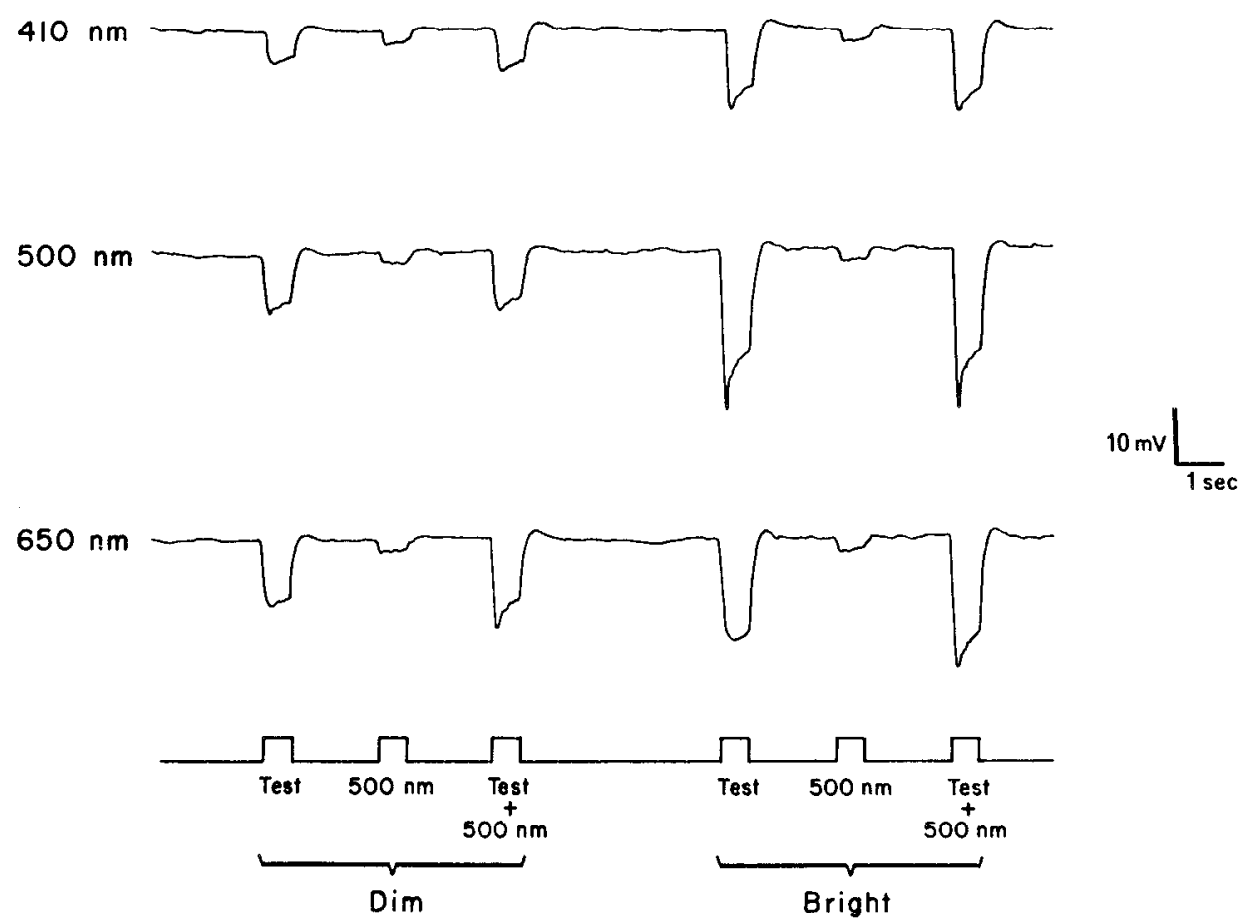

\section{Rod Horizontal Cell}

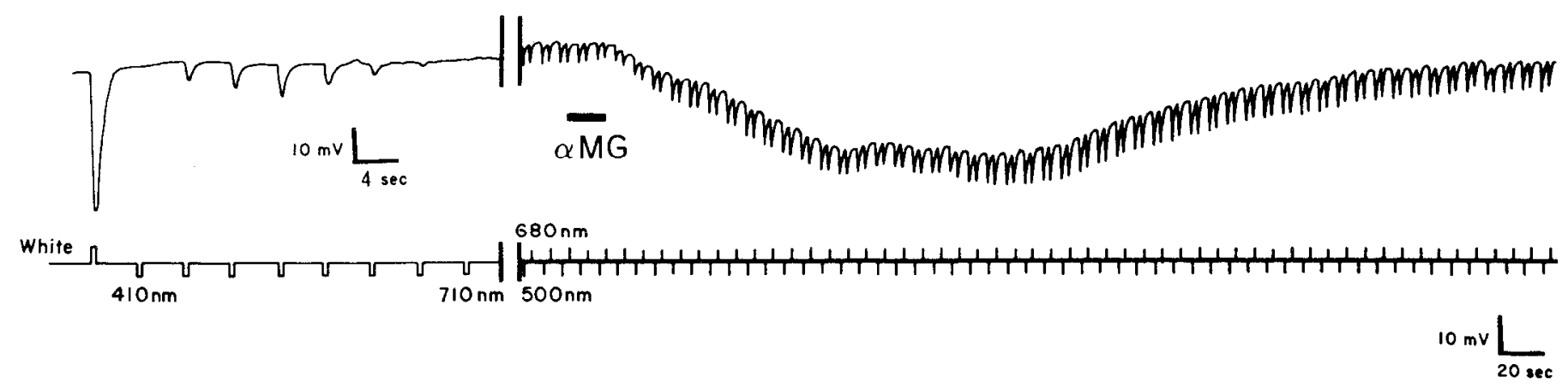

Figure 9. Effects of the acidic amino acid antagonist, $\alpha-M G$, upon the membrane potential and spectral responses of a rod horizontal cell. Conventions are as in Figure 3, except that a spectral response series is illustrated from 410 to $710 \mathrm{~nm}$. Depicted are intensity and spectral response series and the effect of $\alpha-M G$ upon the membrane potential and spectral responses of the cell with recovery. The antagonist hyperpolarized the cell but did not induce a differential response to the $500-\mathrm{nm}$ and $680-\mathrm{nm}$ stimuli. 


\section{6-OHDA Treated Retina}

\section{L-type Cone Horizontal Cell}

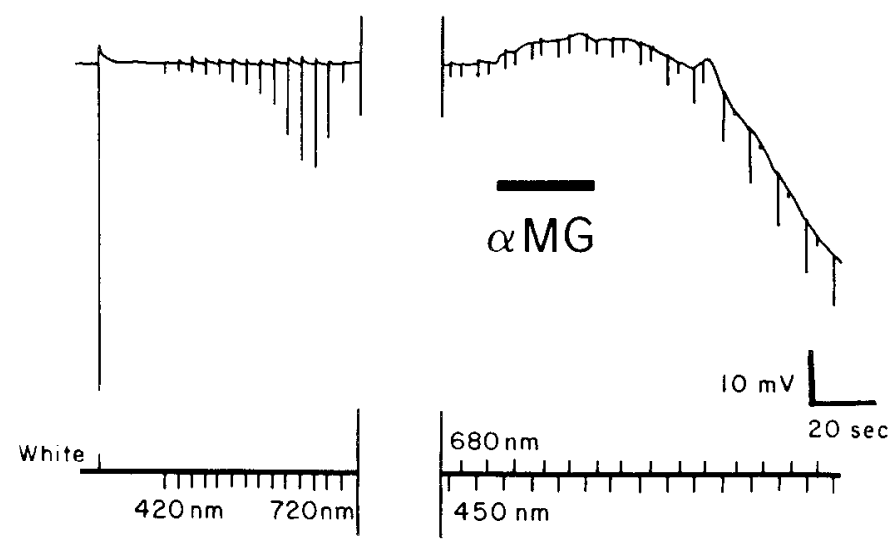

Figure 10. Effects of the acidic amino acid antagonist, $\alpha-M G$, upon the membrane potential and spectral responses of an L-type cone horizontal cell from a retina previously treated with 6-hydroxydopamine (6-OHDA). This procedure depletes the interplexiform cell transmitter, dopamine, from presynaptic terminals. The antagonist hyperpolarized the cell, augmented the response to 450-nm light, and greatly reduced the response to 680 -nm light.

whereas $\mathrm{Co}^{2+}$ treatment produces no such spectral response difference, suggests that red or long wavelength-sensitive cones release a different transmitter than do short wavelength-sensitive cones. This finding is complemented by recent autoradiographic work (Marc and Lam, 1981a; Kleinschmidt, 1982), which showed that red- and green-sensitive cones, but not blue cones, preferentially accumulate labeled glutamate and, to a lesser extent, labeled aspartate. This suggests that red and green cones, but not blue cones, may release one of these two acidic amino acids as a transmitter. Unfortunately, it is still unclear whether the short wavelength cone input(s) to L-type cone horizontal cells is (are) maximally sensitive to green or to blue lights. Recent physiological data from the goldtish (Yang et al., 1982, 1983) indicate the green- and not blue-sensitive cones provide direct input to L-type cone horizontal cells. However, morphological and microspectrophotometric data from the goldfish (Stell and Lightfoot, 1975; Stell, 1980) indicate that both green- and blue-sensitive cones provide input to these horizontal cells. Thus, until definitive identification of the short wavelength-sensitive cone inputs to L-type cone horizontal cells is achieved, some question will remain as to which short wavelength cones are responsible for the effects reported here.

The blue response increase thal occurs with application of acidic amino acid antagonists is observed only at intermediate hyperpolarizations from the dark-adapted level, as shown in Figure $1 B$. The dependency of this phenomenon upon the membrane potential of horizontal cells may indicate that the feedback influence of horizontal celis upon cones is eliminated with large, nearly saturating hyperpolarizations or that blue cone input to $\mathrm{H} 1$ horizontal cells occurs indirectly by way of red-sensitive cones (see below).

Synaptic connections between cones and L-type cone horizontal cells. Because the responses of L-type cone horizontal cells do not increase when small blue spot stimuli are used during amino acid antagonist application, a surround feedback from horizontal cells to cones, which is wavelength dependent, may be postulated. This suggestion is based on the finding in turtles (Baylor et al., 1971; Fuortes et al., 1973; Piccolino and Gerschenfeld, 1980) and fish (Burkhardt, 1977) that inhibitory feedback from horizontal cells to photoreceptors is reduced to a greater extent with larger stimuli that cover the receptive field periphery. Because application of acidic amino acid antagonists reduces or eliminates the red cone input to L-type cone horizontal ( $\mathrm{H} 1$ ) cells, which is their major excitatory input, feedback from $\mathrm{H} 1$ cells to a shorter wavelength-sensitive cone is also reduced or eliminated. Therefore, because the inhibitory feedback from $\mathrm{H} 1$ cells to these short wavelength-sensitive cones is reduced by amino acid antagonist application, the response of $\mathrm{H} 1$ cells to blue lights is increased. Moreover, the reduction in the extent of inhibitory feedback from horizontal cells onto cones during acidic amino acid antagonist application is revealed by the finding that these substances reduce or eliminate the prominent transient in the response waveform of L-type horizontal cells. In general, amino acid antagonist application produces enhancement to short wavelength stimuli of relatively low intensity and an elimination of the prominent transients in the responses to stimuli of relatively high intensity. Both effects can be attributed to a reduction in the tonic inhibitory feedback from $\mathrm{H} 1$ horizontal cells to cones.

In addition to a feedback connection onto cones, morphological studies have suggested that L-type cone horizontal cells receive direct input from short (blue), intermediate (green), and long (red) wavelength-sensitive cones (Stell and Lightfoot, 1975), although the dominant input is undoubtedly provided by red cones, as is evident from the spectral response maximum $(620 \mathrm{~nm})$ of these horizontal cells. Our physiological data suggest that carp L-type cone horizontal cells receive direct input from at least two types of cones, a redsensitive cone and a shorter wavelength-sensitive cone. The presence of at least two cone inputs was observed with two different approaches. First, we found that addition of various spectral backgrounds or flashes elicited different effects upon the response waveform of the cells to spcetral stimuli (sce Figs. 7 and 8). For example, addition of a dim $500-\mathrm{nm}$ flash to a bright red stimulus produced a prominent transient in the response waveform, although none was evident with the red stimulus alone. Second, the presence of at least two direct inputs to L-type cone horizontal cells can be inferred from the differential spectral response effect of acidic amino acid antagonist application (see Figs. 1 and 2). Input from a third cone, that is, a second, shorter wavelength-sensitive cone, was not observed (see Fig. 8), although its influence may be minor and difficult to detect.

These above findings are incorporated into Figure 13, which depicts a model of the synaptic connections between $\mathrm{H} 1$ or L-type cone horizontal cells and red-, blue-, and green-sensitive cones. This model is largely based upon circuitry formulated by Stell and Lightfoot (1975) and originally suggested by Gouras (1972) and Spekreijse and Norton (1970). We have added several modifications to their model. In our case, $\mathrm{H} 1$ cells possess acidic amino acid receptors to interact with the red and green cone transmitter and a different, unknown receptor to interact with the blue cone transmitter. In addition, there are feedback connections from distantly located $\mathrm{H} 1$ horizontal cells onto green-sensitive cones but not onto red or blue cones. Finally, there is a large, direct red cone input and smaller, direct blue and green cone inputs to $\mathrm{H} 1$ horizontal cells or, possibly, an indirect blue cone input to $\mathrm{H} 1$ cells by way of red-sensitive cones. An indirect blue cone input to $\mathrm{H} 1$ cells cannot be eliminated by anatomical findings to date and might explain the fact that the blue response enhancement with amino acid antagonists has only been observed when a response to red light is still present (see Figs. 1 and 2). Alternately, this latter phenomenon can also be explained as in our model, if the feedback connections from $\mathrm{H} 1$ horizontal cells are only made onto green cones and if these green cones release an acidic amino acid as their transmitter.

Although the model of Figure 13 constitutes the most likely explanation of our present data, other similar models cannot be excluded. For example, because physiological evidence for a blue cone input to $\mathrm{H} 1$ horizontal cells in the goldfish is still lacking (Yang et al., 1982, 1983), it is possible that the model of Figure 13 would best be presented without blue cone input to $\mathrm{H} 1$ horizontal cells. However, a model in which only green- and red-sensitive cones synapse onto $\mathrm{Ht}$ cells and release the same acidic amino acid transmitter is difficult to reconcile with the findings reported here. 


\section{Biphasic C-type Horizontal Cells (Red-Green)}
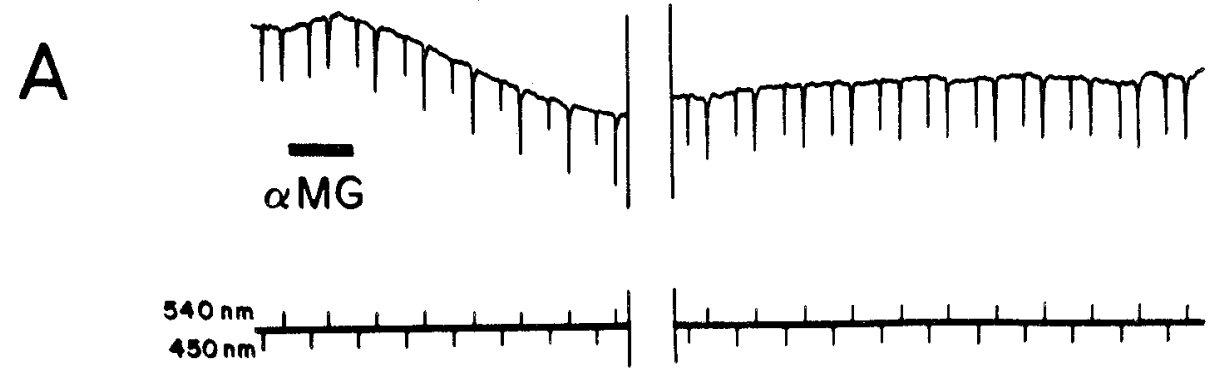

B
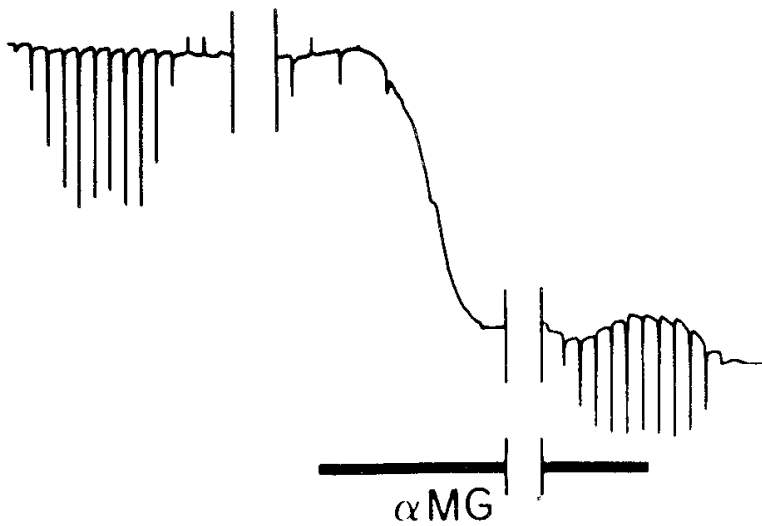

$10 \mathrm{mv} \underbrace{}_{20 \mathrm{sec}}$

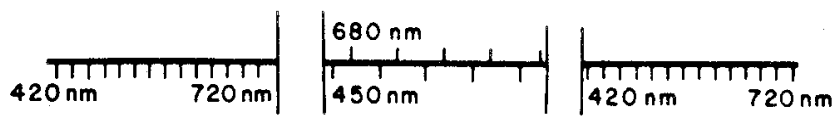

C
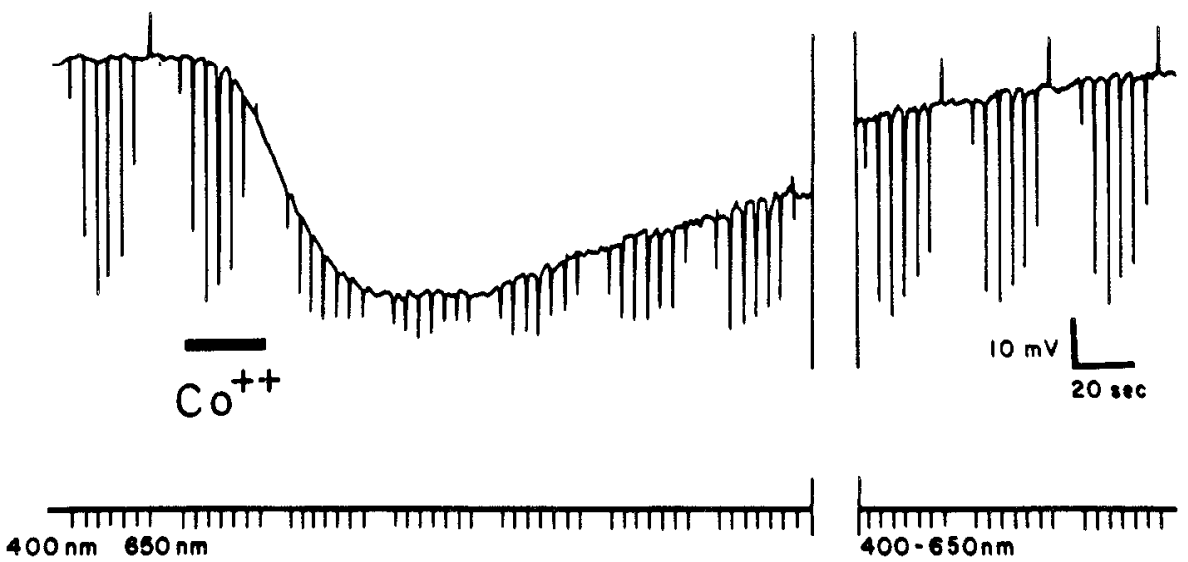

Figure 11. Effects of the acidic amino acid antagonist, $\alpha-M G$, and of $\mathrm{Co}^{2+}$ jons upon the membrane potential and spectral responses of biphasic $\mathrm{C}$-type horizontal cells. Conventions are as in Figure 3, except that in $C$ the spectral response series are from 400 to $650 \mathrm{~nm}$. $A$, Effect of $\alpha$-MG upon the membrane potential and spectral responses with recovery. The drug hyperpolarized the cell, augmented the response to 540-nm light, and reduced the response to 450-rim light. $B$, Effect of $\alpha-\mathrm{MG}$ as revealed by a comparison of spectral response series before and during drug application. The depolarizing responses to 680 and $720 \mathrm{~nm}$ of light were abolished by the drug and the depolarizing response to $650 \mathrm{~nm}$ of light became a hyperpolarization. $C$, Effect of $\mathrm{Co}^{2+}$ ions upon membrane potential and spectral responses with recovery. $\mathrm{Co}^{2+}$ ion application also hyperpolarized the cell and changed the depolarizing response to $650 \mathrm{~nm}$ of light into a hyperpolarizing response. 
Figure 12. Effects of the acidic amino acid antagonist, $\alpha-\mathrm{MG}$, and of $\mathrm{Co}^{2+}$ ions upon the membrane potential and spectral responses of triphasic C-type horizontal cells. Conventions are as in Figure 3. A, Spectral response series and effect of $\alpha$ MG with recovery. The antagonist hyperpolarized the cell and changed the depolarizing response to $540-\mathrm{nm}$ light into a hyperpolarizing response. $B$, Effect of $\mathrm{Co}^{2+}$ ions on the same cell 2 min later with recovery. $\mathrm{Co}^{2+}$ application produced effects similar to those of $\alpha$-MG. C, Spectral response series and effect of $\alpha-M G$ on a different cell. The antagonist abolished the depolarizing component in the response of the cell to the $520-\mathrm{nm}$ stimulus.
A
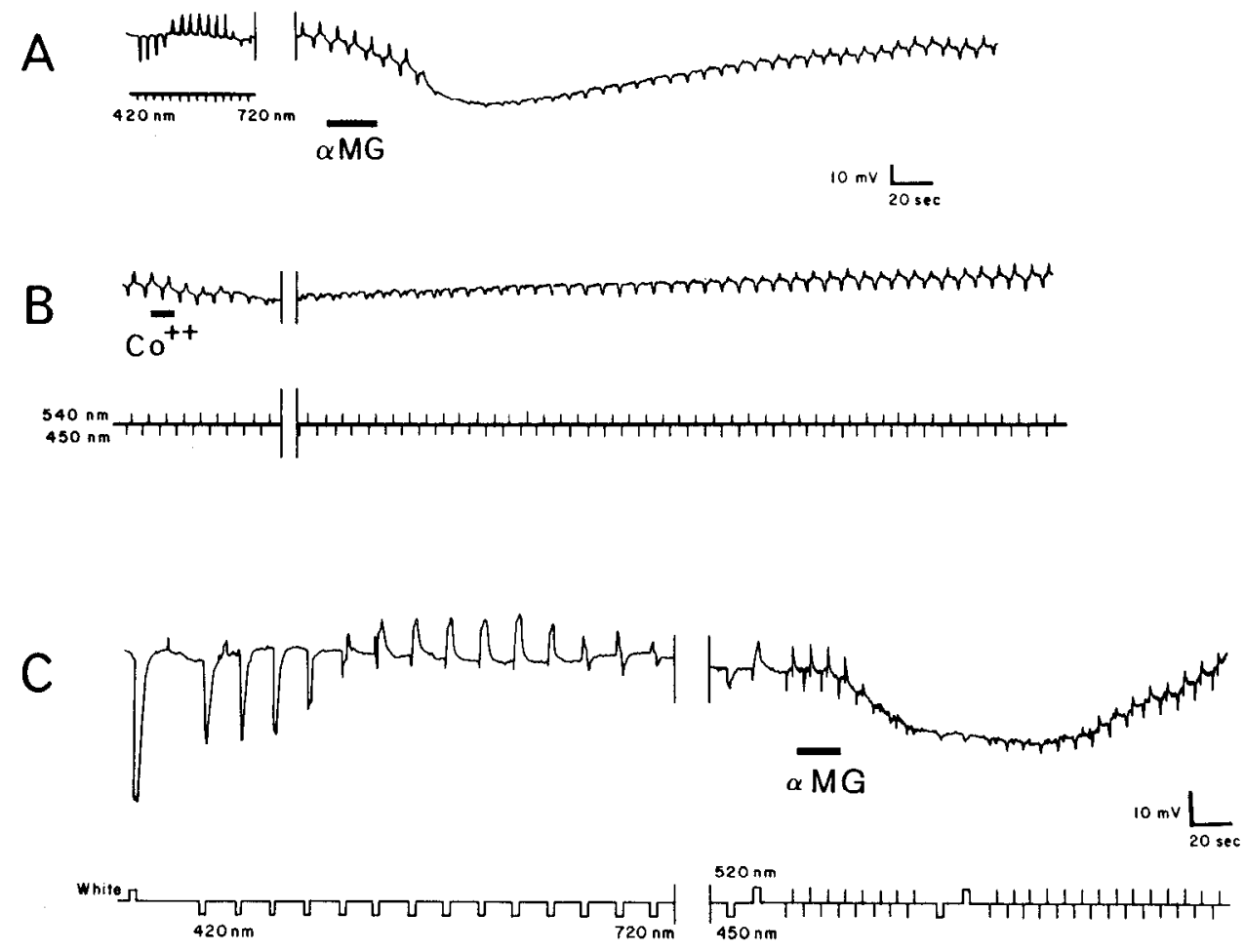

That is, to account for the response enhancement to short wavelength stimuli during acidic amino acid antagonist application, we must assume that low doses of the amino acid antagonists have a stronger effect on the feedback pathway than on the green-sensitive conc input to the $\mathrm{H} 1$ horizontal cell. In fact, although it is difficult to rule out the possibility that the acidic amino acid antagonists, $\alpha-M G$ and $\alpha-\mathrm{AA}$, have nonspecific direct actions on the feedback pathway from $\mathrm{H} 1$ horizontal cells to cones, we have observed that these substances block the depolarizing effects of glutamate, aspartate, and kainate, in a manner similar to that of $N$-methyl-D-aspratate (Arie et al., 1984). Therefore, $\alpha$-MG and $\alpha$-AA are effective antagonists at the acidic amino acid-binding sites of the horizontal cell membrane.

The model of Figure 13 does account, in large part, for the findings reported here and for those of others concerned with the outer retina of the fish. In particular, the autoradiographic work of Marc and Lam (1981a) and Kleinschmidt (1982) and our finding that amino acid antagonist application differentially blocks the responses of L-type cone horizontal cells to long wavelength stimuli compared to short wavelength stimuli suggest that long and short wavelengthsensitive cones in the fish retina release different transmitters Although large, saturating applications of the amino acid antagonists, $\alpha-\mathrm{MG}$ and $\alpha-\mathrm{AA}$, can occasionally completely block all responses to spectral stimuli, as shown in Figure $2 B$, in the vast majority of cases, the response to blue light remained noticeably larger than the response to red light during hyperpolarization due to antagonist application (e.g., Figs. 1 and $2 A$ ). The fact that large doses of $\alpha$-MG and $\alpha$-AA can sometimes diminish the responses of L-type cone horizontal cells to blue lights and can hyperpolarize triphasic C-type horizontal cells (Fig. 12), which presumably receive only blue cone input (Stell and Lightfoot, 1975), suggests that the blue cone transmitter may resemble the transmitter of the red and green cones so that the acidic amino acid antagonists can partially block its effects.

The suggeslion in Figure 13 that $\mathrm{H} 1$ horizontal cells make feedback connections onto green-sensitive cones but not onto red or blue cones accounts for the finding that acidic amino acid antagonist application does not enhance the blue light response of triphasic C- type horizontal cells (Fig. 12) and for the finding that the blue light response increase that occurs with antagonist application is observed only at intermediate hyperpolarizations from the dark-adapted level when a response to red light is still present (Figs. 1 and 2). In addition, Toyoda ct al. (1982) have reported that polarization of $L$ type cone horizontal cells does not elicit any detectable effect from triphasic C-type horizontal cells, a finding which suggests that a feedback pathway from $\mathrm{H} 1$ or L-type cone horizontal cells to blue cones is not present. Conversely, polarization of L-type cone horizontal cells does elicit potential changes in biphasic C-type horizontal cells, a finding that indicates the presence of a feedback connection between $\mathrm{H} 1$ horizontal cells and green-sensitive cones.

The feedback connection between $\mathrm{H} 1$ horizontal cells and cones has recently been investigated by the application of GABA, a putative transmitter of these horizontal cells (Lam, 1972; Lam et al., 1979;

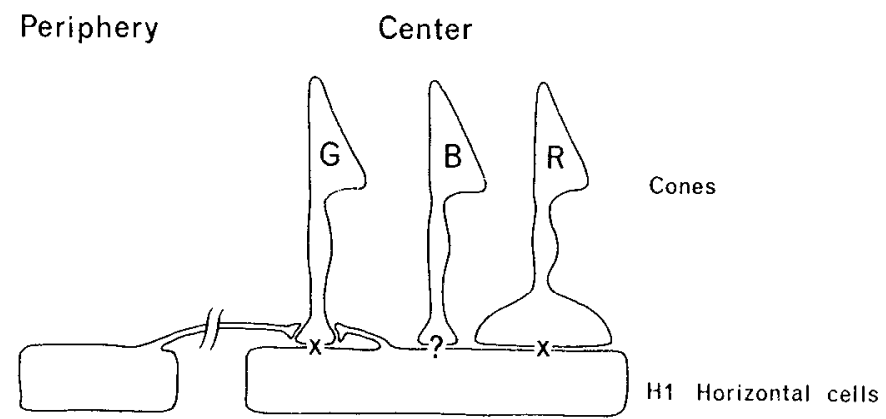

? - unknown receptor

$X$ - acidic amino acid receptor

Figure 13. A model of the synaptic connections between L-type cone $(H 1)$ horizontal cells and red- $(R)$, blue - $(B)$, and green- $(G)$ sensitive cones. Centrally and peripherally located $\mathrm{H} 1$ horizontal cells are depicted. See the text for details. 
Murakami et al., 1978, 1982; Wu and Dowling, 1980) and by the application of the GABA antagonists, picrotoxin and bicuculline (Murakami et al., 1982). In general, GABA application produces spectral effects upon $\mathrm{H} 1$ horizontal cell responses similar to those of $\alpha-\mathrm{MG}$ and $\alpha-\mathrm{AA}$, but with relatively small membrane hyperpolari7ations, presumably because GABA desensitizes the feedback pathway. The effects of picrotoxin and bicuculline are the reverse of those of GABA (Murakami et al., 1982).

A comparison of the effects of GABA, on the one hand, and of $\alpha-\mathrm{MG}$ and $\alpha$-AA, on the other, is illuminating. High effective concentrations of GABA and low effective concentrations of $\alpha-\mathrm{MG}$ and $\alpha$ $A A$ both produce small hyperpolarizations of L-type cone horizontal cells and an enhancement of the responses of these cells to short wavelength stimuli. Higher doses of $\alpha-M G$ and $\alpha$-AA further hyperpolarize L-type cone horizontal cells and reduce the responses of these cells to red lights more than to blue lights. In other words, relatively low concentrations of the acidic amino acid antagonists partially reduce the influence of the long wavelength-sensitive cone acidic amino acid transmitter upon L-type cone horizontal cells and thus indirectly reduce the influence of the feedback pathway of horizontal cells onto cones. Relatively higher concentrations of $\alpha$ $M G$ and $\alpha$-AA completely reduce the influence of the acidic amino acid transmitter upon L-type cone horizontal cells so that the responses of these horizontal cells to red lights is reduced morc than the responses to blue lights. As mentioned above, the selectivity of $\alpha-\mathrm{MG}$ and $\alpha$-AA to the acidic amino acid receptor sites of cone horizontal cells is demonstrated by their ability to block the depolarizing effects of glutamate, aspartate, and kainate.

Nithough $\alpha-M G$ and $\alpha-A A$ are potent antagonists at the acidic amino acid receptor sites of carp cone horizontal cells, the antagonist activity of these compounds is relatively low at acidic amino acid receptor sites elsewhere in the central nervous system (Foster and Fagg, 1984). Because $N$-methyl-D-aspartate, a potent agonist at some acidic amino acid receptor sites in the central nervous system, also acts as an antagonist to carp cone horizontal cells (Ariel et al., 1984; M. Ariel, S. C. Mangel, and J. E. Dowling, submitted for publication), it thus appears likely that the acidic amino acid receptors of carp cone horizontal cells are unlike other acidic amino acid receptors previously described in the central nervous system.

The effects of acidic amino acid antagonists upon the spectral responses of L-type cone horizontal cells are probably mediated only by outer retinal pathways. Inner retinal influence upon horizontal cells is possible via interplexiform cells (Ehinger et al., 1969; Dowling and Ehinger, 1978) and may modulate the degree of electrical coupling between horizontal cells (Teranishi et al., 1983, 1984). However, we have found that prior intraocular injection of 6-hydroxydopamine, a treatment that depletes the interplexiform cell transmitter, dopamine, from presynaptic terminals, does not affect the spectral response effects of acidic amino acid antagonists in any observable manner. Thus, the response enhancement to. low wavelength stimuli during acidic amino acid antagonist application cannot be attributed to an indirect effect of these druys upon horizontal cell coupling.

Recent data have indicated that a second type of interplexiform cell in the goldfish may utilize glycine as a transmitter (Marc and Lam, 1981b). However, it is unlikely that the inner retina influences L-type cone horizontal cells via this type of interplexiform cell, because glycine application affects the membrane potential and spectral responses of C-type cone horizontal cells but does not affect $L$-type cone horizontal cells (Wu and Dowling, 1980).

It is also unlikely that the spectral effects of $\alpha-M G$ and $\alpha$-AA result from a nonspecific drug effect upon coupling between $\mathrm{H} 1$ horizontal cells. Specifically, the enhancement of the responses of L-type cone horizontal cells to full field blue lights that is observed with application of GABA (Murakami et al., 1982) and the acidic amino acid antagonists, $\alpha-M G$ and $\alpha$-AA, is not seen with application of dopamine, a substance that is known to uncouple $\mathrm{H} 1$ horizontal cells (Mangel and Dowling, 1984; Teranishi et al., 1984).
The blue response increase during amino acid antagonist application is probably not related to the phenomenon of mutual spectral response enhancement or to nonlinearities of the horizontal cell membrane. Previous workers (Maksimova et al., 1966; Naka and Rushton, 1966b; Laufer and Negishi, 1978) have reported that horizontal cell responses to green lights become enhanced with the addition of a red background stimulus and that the reverse also occurs. This phenomenon has been attributed to the nonlinearity of the horizontal cell nonsynaptic membrane, which is voltage dependent and amplifies the graded potentials of the subsynaptic membrane (Byzov et al., 1977). However, the blue response enhancement that occurs with amino acid antagonist application, in contrast to the phenomenon of mutual spectral response enhancement, is wavelength dependent and of greater magnitude (cf. Naka and Rushton, 1966b, Fig. 1, and Figs 1, 2, and $4 A$ here). We did, in fact, observe small spectral response enhancements occasionally during recovery from the effects of drugs (Figs. $4 B$ ) or during $\mathrm{Co}^{2+}$ treatment. Because these increases were in response to both blue and red stimuli, they may be related to the phenomenon of mutual spectral response enhancement and to a nonlinearity of the horizontal cell nonsynaptic membrane.

C-type cone horizontal cells. Inhibitory feedback pathways from horizontal cells to cones probably serve as the basis for the depolarizing responses of C-type horizontal cells (Stell and Lightfoot, 1975; Toyoda and Kujiraoka, 1982). The transformation of these depolarizing responses into hyperpolarizing responses has been reported previously following GABA application (Murakami et al., 1978,1982 ) and after picrotoxin or bicuculline application (Djamgoz and Ruddock, 1979; Murakami et al., 1982). We find that application of acidic amino acid antagonists also inverts depolarizations into hyperpolarizations for C-type horizontal cells.

However, it is interesting that $\mathrm{Co}^{2+}$ application produces a response inversion similar in every respect to that seen with the acidic amino acid antagonists but that a hyperpolarization of the horizontal cell membrane by light adaptation does not produce such a response inversion. These findings suggest that postsynaptic hyperpolarization of the horizontal cell membrane potential by itself is not sufficient to eliminate differentially the depolarizing responses of these cells. Therefore, the effect of $\mathrm{Co}^{2+}, \mathrm{GABA}$, picrotoxin, and the acidic amino acid antagonists appears to be drug related and possibly due, in some unknown way, to the characteristics of the feedback pathway from horizontal cells to cones.

\section{References}

Ariel, M., E. M. Lasater, S. C. Mangel, and J. E. Dowling (1984) On the sensitivity of $\mathrm{H} 1$ horizontal cells of the carp retina to glutamate, aspartate and their agonists. Brain Res. 295: 179-183.

Baylor, D. A., M. G. F. Fuortes, and P. M. O'Bryan (1971) Receptive field of cones in the retina of the turtle. J. Physiol. (Lond.) 214: 265-294

Burkhardt, D. A. (1977) Responses and receptive-field properties of cones in perch retina. J. Neurophysiol. 40: 53-62.

Byzov, A. L., Y. A. Trifonov, L. M. Chailahian, and K. W. Golubtzov (1977) Amplification of graded potentials in horizontal cells of the retina. Vision Res. 17: 265-273.

Cervetto, L., and E. F. MacNichol, Jr. (1972) Inactivation of horizontal cells in the turtle retina by glutamate and aspartate. Science 178: 767-768.

Cervetto, L., and M. Piccolino (1974) Synaptic transmission between photoreceptors and horizontal cells in the turtle retina. Science 183: 417-419.

Cohen, J. L., and J. E. Dowling (1983) The role of the interplexiform cell: Effects of 6-hydroxydopamine on the spatial properties of carp horizontal cells. Brain Res. 264: 307-310.

Djamgoz, M. B. A., and K. H. Ruddock (1979) Effects of picrotoxin and strychnine on fish retinal S-potentials: Evidence for inhibitory control of depolarizing responses. Neurosci. Lett. 12: 329-334.

Dowling, J. E., and B. Ehinger (1978) The interplexiform cell system. I Synapses of the dopaminergic neurons of the goldfish retina. Proc. R. Soc. Lond. (Biol.) 201: 7-26.

Dowling, J. E., and I I. Ripps (1971) S-Potentiais in the skate retina: Intracellular recording during light and dark adaptation. J. Gen. Physiol. 58: 163-189. 
Dowling, J. E., and H. Ripps (1972) Adaptation in skate photoreceptors. J. Gen. Physiol. 60: 698-719.

Ehinger, B., B. Falck, and A. M. Laties (1969) Adrenergic neurons in teleost retina. Z. Zellforsch. 97: 285-297.

Foster, A. C., and G. E. Fagg (1984) Acidic amino acid binding sites in mammalian neuronal membranes: Their characteristics and relationship to synaptic receptors. Brain Res. Rev. 7: 103-164.

Fuortes, M. G. F., E. A. Schwartz, and E. J. Simon (1973) Colour dependence of cone responses in the turtle retina. J. Physiol. (Lond.) 234: 199-216

Gouras, P. (1972) S-Potentials. In Handbook of Sensory Physiology. Vol. VIl, Part 2: Physiology of Photoreceptor Organs, M. G. Fuortes, ed., pp. 513520, Springer-Verlag, Berlin.

Hedden, W. L., Jr., and J. E. Dowling (1978) The interplexiform cell system. II. Effects of dopamine on goldfish retinal neurones. Proc. R. Soc. Lond. (Biol.) 201: 27-55.

Ishida, A. T., and G. L. Fain (1981) D-Aspartate potentiates the effects of Lglutamate on horizontal cells in goldfish retina. Proc. Natl. Acad. Sci. U. S. A. 78: $5890-5894$

Kaneko, A. (1970) Physiological and morphological identification of horizontal, bipolar and amacrine cells in goldfish retina. J. Physiol. (Lond.) 207: 623633.

Kaneko, A., and M. Yamada (1972) S-potentials in the dark-adapted retina of the carp. J. Physiol. (Lond.) 277: 261-273.

Kleinschmidt, J. (1982) Uptake of aspartate and glutamate into goldfish photoreceptors and Muller cells. Invest. Ophthalmol. Vis. Sci. Suppl. 22: 184.

Lam, D. M. K. (1972) The biosynthesis and content of $\gamma$-aminobutyric acid in the goldfish retina. J. Cell Biol. 54: 225-231.

Lam, D. M. K., Y. Y. T. Su, L. Swain, R. E. Marc, C. Brandon, and Y. U. Wu (1979) Immunocytochemical localization of L-glutamic acid decarboxylase in the goldfish retina. Nature 278: 565-567.

Lasater, E. M., and J. E. Dowling (1982) Carp horizontal cells in culture respond selectively to L-glutamate and its agonists. Proc. Natl. Acad. Sci. U. S. A. 79: 936-940.

Laufer, M., and K. Negishi (1978) Enhancement of hyperpolarizing S-potentials by surround illumination in a teleost retina. Vision Res. 18: 10051011.

MacNichol, E. F., Jr., and G. Svaetichin (1958) Llectric responses from the isolated retina of fishes. Am. J. Ophthalmol. 46: 26-39.

Maksimova, E. M., V. V. Maksimov, and O. Yu Orlov (1966) Amplified irleraclion between the signals from cell receptors and sources of $\mathrm{S}$ potentials. Biofizika 11: $472-477$

Mangel, S. C., and J. E. Dowling (1984) Effects of dopamine and VIP on fish cone horizontal cells. Soc. Neurosci. Abstr. 10: 835

Marc, R. E., and D. M. K. Lam (1981a) Uptake of aspartic and glutamic acid by photoreceptors in the goldfish retina. Proc. Natl. Sci. U. S. A. 78: 71857189.

Marc, R. E., and D. M. K. Lam (1981b) Glycinergic pathways in the goldfish retina. J. Neurnsci. 1: 15?-165

Mitari, G., T. Asano, and Y. Miyake (1974) Identification of five types of Spotential and their corresponding generating sites in the horizontal cells of the carp retina. Jpn. J. Ophthalmol. 18: 161-176.

Murakami, M., K. Ohtsu, and T. Ohtsuka (1972) Effects of chemical on receptors and horizontal cells in the retina. J. Physiol. (Lond.) 227: 899913

Murakami, M., Y. Shimoda, and K. Nakatani (1978) Effects of GABA on neuronal activities in the distal retina of the carp. Sens. Processes 2: 334 338.
Murakami, M., Y. Shimoda, K. Nakatani, F. Miyachi, and S. Watanabe (1982) GABA-mediated negative feedback and color opponency in carp retina Jpn. J. Physiol. 32: 927-935.

Naka, K. I., and W. A. H. Rushton (1966a) S-potentials from colour units in the retina of fish (Cyprinidae). J. Physiol. (Lond.) 185: 536-565.

Naka, K. I, and W. A. H. Rushton (1966b) S-potentials from luminosity units in the retina of fish (Cyprinidae). J. Physiol. (Lond.) 185: 587-599.

Naka, K. I., and W. A. H. Rushton (1967) The generation and spread of Spotential in fish (Cyprinidae) J. Physiol. (Lond.) 192: 437-461.

Negishi, K., T. Teranishi, and S. Kato (1981) Similarity in spatial distribution between dopaminergic and indoleamine-accumulating cells of the carp retina. Acta Histochem. Cytochem. 14: 449-460.

O'Bryan, P. M. (1973) Properties of the depolarizing synaptic potential evoked by peripheral illumination in cones of the turtle retina. J. Physiol. (Lond.) 235: 207-233.

Piccolino, M., and H. M. Gerschenfeld (1980) Characteristics and ionic processes involved in feedback spikes of turtle cones. Proc. R. Soc. Lond. (Binl.) 206: 439-463

Spekreijse, H., and A. Norton (1970) The dynamic characteristics of colorcoded S-potentials. J. Gen. Physiol. 56: 1-15.

Stell, W. K. (1980) Photorcccptor-specific pathways in goldfish retina: A world of color, a wealth of connections. In Colour Vision Deficiencies V. G. Verriest, ed., pp. 1-14, Adam Hilger, Bristol, England.

Stell, W. K., and D. O. Lightlloul (1975) Color-specific interconnections of cones and horizontal cells in the retina of the goldfish. J. Comp. Neurol. 159: 473-502.

Teranishı, 1., K. Negishi, and S. Kato (1983) Dopamine modulates S-potential amplitude and dye-coupling between external horizontal cells in carp retina. Nature 301: 243-246

Teranishi, T., K. Negishi, and S. Kato (1984) Regulatory effect of dopamine on spatial properties of horizontal cells in carp retina. J. Neurosci. 4: 12711280.

Tomita, T. (1965) Electrophysiological study of the mechanisms subserving color coding in the fish retina. Cold Spring Harbor Symp. Quant. Biol. 30 $559-566$.

Toyoda, J., and T. Kujiraoka (1982) Analyses of bipolar cell responses elicited by polarization of horizontal cells. J. Gen. Physiol. 79: 131-145

Toyoda, J., T. Kujiraoka, anid M. Fujirnolo (1982) The opponent color process and interaction of horizontal cells. In The S-Potential, B. J. Drujan and M. Laufer, eds., pp. 151-160, Alan R. Liss, Inc., New York.

Watling, K. J., D. Parkinson, and J. t. Dowling (1982) Effects of intraocular injections of 6-hydroxydopamine on dopamine-dependent cyclic AMP accumulation in intact pieces of carp retina. Brain Res. 253: 334,-336.

Werblin, F. S., and J. E. Dowling (1969) Organization of the retina of the mudpuppy, Necturus maculosis. II. Intracellular recording. J. Neurophysiol. 32: $339-355$.

Wu, S. M., and J. E. Dowling (1978) L-Aspartate: Evidence for a role in cone photoreceptor synaptic transmission in the carp retina. Proc. Natl. Acad. Sci. U. S. A. 75: 5205-5209.

Wu, S. M., and J. E. Dowling (1980) Effects of GABA and glycine on the distal cells of the cyprinid retina. Brain Res. 199: 401-414.

Yang, X. -L., M. Tauchi and A. Kaneko (1982) Quantitative analysis of photoreceptor inputs to external horizontal cells of the goldfish retina. Jpn. J. Physiol. 32: 399-420.

Yang, X. -L., M. Tauchi, and A. Kaneko (1983) Convergence of signals from red-sensitive and green-sensitive cones onto L-type external horizontal cells of the goldfish retina. Vision Res. 23: 371-380. 